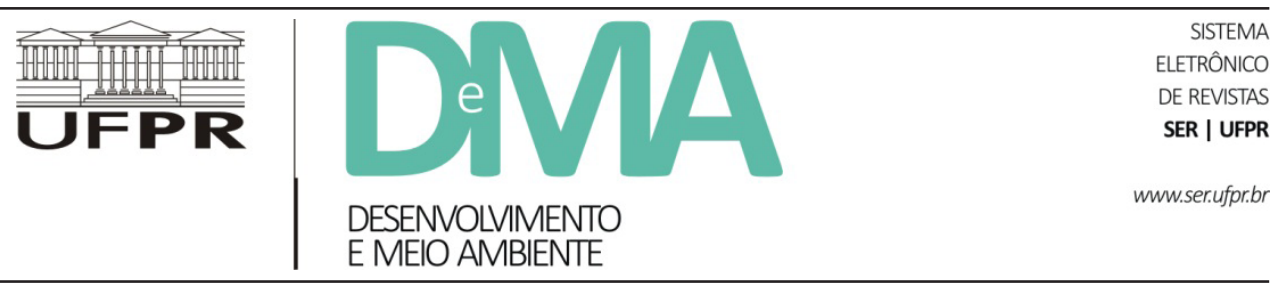

\title{
Gestão integrada e participativa em ambientes costeiros: estudo de caso do Projeto Orla no município de Balneário Rincão, SC, Brasil
}

\section{Integrated and Participative Management in Coastal Environments: Case Study of "Projeto Orla" at Balneário Rincão, SC, Brazil}

\author{
Carlyle Torres Bezerra de MENEZES ${ }^{1 *}$, Luana da Silva LUMERTZ ${ }^{1}$, Amanda Bellettini MUNARI ${ }^{1}$, Gianfranco \\ CENI $^{1}$ \\ ${ }^{1}$ Universidade do Extremo Sul Catarinense (UNESC), Criciúma, SC, Brasil. \\ *E-mail de contato: cbm@unesc.net
}

Artigo recebido em 3 de junho de 2016, versão final aceita em 11 de agosto de 2016.

RESUMO: A zona costeira brasileira é singular por sua histórica importância socioeconômica e sua riqueza natural, onde atividades de elevado impacto poluidor coexistem com recursos ambientais de extrema importância. Na tentativa de agregar uma vertente participativa na política de gestão do território costeiro, o plano de gestão do governo federal denominado "Projeto Orla" apresenta-se como uma proposta de política pública descentralizadora e integrada. Nesse contexto, o presente trabalho buscou contribuir na avaliação deste instrumento de gestão ambiental, considerando como estudo de caso a implantação do Projeto Orla no município de Balneário Rincão (litoral sul de Santa Catarina, Brasil). A partir da metodologia de observação participante e da análise de documentos de fontes primárias, identificaram-se os seguintes aspectos: (1) a participação da comunidade no processo de gestão territorial é fundamental para garantir o atendimento das necessidades e peculiaridades de cada região; (2) a integração dos instrumentos de gestão é de extrema importância para diminuir os conflitos no uso e ocupação do território; e (3) a educação ambiental é o principal instrumento de sensibilização para a transição do modelo atual de consumo para o modelo ambientalmente sustentável.

Palavras-chave: co-manejo; educação ambiental; sensibilização pública; comunidades tradicionais; Área de Proteção Ambiental.

ABSTRACT: The Brazilian coastal zone is singular by its historical socioeconomic importance and natural richness, where highly polluting activities coexists with valuable environmental resources. In an attempt to add a participative quality in the management politics of this territory, the management plan of federal government named Projeto Orla appears as a decentralizing and integrated politic. In this context, the present work aims to contribute as an assessment of this management mechanism considering, as study case, the implementation of Projeto Orla in the Balneário Rincão municipality (Santa Catarina's southern coast, Brazil). Based on participant 
observation and first source documentation analysis, a group of assumptions was generated, as follows: (1) The community participation in the management process is intrinsic to assure the goal of regional necessities and peculiarities; (2) the integration of management mechanisms is highly important to reduce the territory use and occupancy conflicts; and (3) the environmental education is the main awareness tool to transpose from the actual consumption model to the environmentally sustainable model.

Keywords: co-management; environmental education; public awareness; traditional communities; environmental protection area.

\section{Introdução}

Os ambientes marinho-costeiros do Brasil são aqueles que mais sofreram nos últimos anos com o processo de ocupação humana desordenada, o que determinou um considerável processo de degradação ambiental, pela crescente pressão sobre os recursos naturais e pela capacidade limitada desses ecossistemas absorverem os impactos resultantes (Moraes, 2007).

Acompanhando um padrão mundial de ocupação territorial, o ambiente costeiro brasileiro apresenta os maiores contingentes populacionais, de modo que cerca de $26,6 \%$ dos habitantes do país (aproximadamente 50,7 milhões de pessoas) residem em municípios da zona costeira (IBGE, 2011). O modelo de crescimento, principalmente na década de 1960, alocou esforços para o desenvolvimento de regiões específicas, proporcionando, no entanto, uma ocupação desordenada (Marroni \& Asmus, 2005). A atividade migratória da população para o litoral, em busca de melhores oportunidades, gerou graves problemas de cunhos sociais, urbanístico, político, econômico e ambiental.

No contexto de uma análise da evolução do processo de ocupação territorial e urbanização, logo após o processo de redemocratização do país e a promulgação da Constituição Federal de 1988, foram constituídos no Brasil diversos instrumentos de gestão pública ambiental, que contribuíram para o estabelecimento de um quadro normativo e legal com relativa ordenação, mesmo na ocorrência de retrocessos, a exemplo do Novo Código Florestal (Brasil, 2012). Nesse contexto, podemos destacar como avanços no processo de gestão a implantação de Planos Diretores (Cymbalista \& Santoro, 2009), o Zoneamento Econômico-Ecológico (MMA, 2011), os Planos de Manejo de Unidades de Conservação (MMA, 2004), os Planos de Bacia Hidrográfica (Brasil, 1997), os Planos de Gerenciamento Costeiro (Brasil, 1998), entre outros.

Entretanto, mesmo com a existência deste arcabouço normativo e legal, a qualidade e o acesso às informações utilizadas na estruturação desses instrumentos de gestão devem ser questionados. Percebe-se que quando sua origem provém exclusivamente de órgãos governamentais e/ou instituições de pesquisa e ensino articuladas aos sistemas de gestão, o restante da comunidade (stakeholders majority) assume uma participação secundária ou inexistente na contribuição de seu ponto de vista, considerando de maneira mais ampla a gestão e o planejamento de seu território e, dentro desse, o próprio processo de tomadas de decisões (Seixas, 2005).

$\mathrm{Na}$ tentativa de reverter os impactos socioambientais e, também, direcionar a ocupação e o uso da zona costeira para uma utilização racional de seus recursos, faz-se necessária a busca de estratégias alternativas de desenvolvimento, na perspectiva da gestão do patrimônio natural de forma prudente e equitativa (Vieira et al., 2005). 
Nesse processo, determinados instrumentos de estruturação são necessários ao gerenciamento eficiente destes territórios (Vieira et al., 2010), bem como para a resiliência dessas ações (Allen et al., 2011). Neste sentido, vem emergindo nos últimos anos o enfoque de ecodesenvolvimento por parte de vários autores e continua ainda hoje alimentando o debate acadêmico sobre o binômio ecologia \& desenvolvimento, além de representar um contraponto transgressivo com relação ao ainda hegemônico modelo de desenvolvimento capitalista (Vieira et al., 2005; Sachs, 2007).

Considerando a estruturação e o planejamento sistêmicos do ambiente costeiro, despontam mudanças de paradigmas no contexto ambiental, incluindo uma demanda por modelos de gestão descentralizada e compartilhada. A forma indicada é participando das definições e tomadas de decisões, tendo uma linha de conexão com os órgãos de gestão que garanta não só o reconhecimento e a utilidade do seu conhecimento não formal, mas que a conduza a um processo de participação na direção da co-gestão (Marroni \& Asmus, 2005).

Fomentando a estratégia de gestão participativa, o governo federal brasileiro implementou, a partir do ano de 2001, o Projeto de Gestão Integrada da Orla Marítima (Projeto Orla), destinado ao planejamento do uso e da ocupação da zona costeira do país. O principal objetivo deste projeto é descentralizar as políticas ambiental e patrimonial do Governo Federal na gestão dos espaços litorâneos, buscando o fortalecimento da capacidade de atuação dos diferentes atores do setor público e privado por meio da gestão integrada e participativa (Marroni \& Asmus, 2005).

O Projeto Orla, tendo como premissa básica a gestão descentralizada, define princípios e procedimentos de ação compartilhada entre as três esferas governamentais (Federal, Estadual e Municipal) juntamente à participação da sociedade civil (MMA/ MP, 2005). Dentro de sua estrutura, as coordenações nos três níveis (cada qual com composição, atribuições e objetivos específicos) contam com colegiados de apoio que têm por função principal dar suporte às ações das coordenações. No nível nacional, tem-se o Grupo de Integração do Gerenciamento Costeiro (GI-GERCO), formado por diferentes instituições atuantes na zona costeira. O colegiado estadual está representado pela Comissão Técnica Estadual (CTE), composta pelas secretarias estaduais, com a participação de representações como o IBAMA, Capitania dos Portos, universidades e centros de pesquisa. Em estados que já instituíram o Plano Estadual de Gerenciamento Costeiro (PEGC), a CTE deve ser formada pelo colegiado costeiro estabelecido pelo Plano. Em âmbito municipal, o colegiado está no Comitê Gestor da Orla. Este deve se constituir no núcleo de articulação e deliberação do Projeto, com representação paritária entre órgãos públicos do município e a Sociedade Civil Organizada (MMA/MP, 2005). Tal ajuste é pontuado como fundamental para a divisão, estimulando a implantação de parcerias, o aprimoramento das rotinas de operação e o encaminhamento das demandas e dos produtos gerados (MMA/MP, 2005).

A fim de subsidiar a construção de Projetos que comportem as necessidades de gestão em um panorama complexo da orla brasileira, o Ministério do Meio Ambiente, em articulação com o Ministério do Planejamento, Orçamento e Gestão, publicou cinco guias de procedimentos técnicos (MMA/ MP, 2004; 2005; 2006a; 2006b; Nakano, 2006). A essência dos guias incorpora uma série de estudos preliminares de análise da base legal, tendo como suporte a Agenda 21 e outros documentos da Organização das Nações Unidas (ONU) (MMA, 2004).

Têm-se como exemplos práticos dos instrumentos legais incorporados pelo Projeto Orla a defi- 
nição da Zona Costeira como "patrimônio nacional" (Art. 225, § $4^{\circ}$ da Constituição Federal de 1988) e como "[...] o espaço geográfico de interação do ar, do mar e da terra, incluindo seus recursos renováveis ou não, abrangendo uma faixa marítima e outra terrestre [...]" (Brasil, 1998), e, sobretudo, o Decreto Federal 5.300/04, que cria regras mais específicas para o uso e a ocupação da zona costeira (Brasil, 2004). Seu conteúdo delimita a zona costeira em direção ao mar pela isóbata de $10 \mathrm{~m}$, enquanto que, em direção à terra, restringe-a à distância (em linha reta) de $50 \mathrm{~m}$ para áreas urbanizadas e de $200 \mathrm{~m}$ para áreas não urbanizadas, a partir da linha da maré alta (ou do limite do ecossistema terrestre adjacente).

Diante destes instrumentos de planejamento e gestão apresentados como mecanismos de desenvolvimento sustentável da zona costeira no Brasil e, mais especificamente, na perspectiva de implantação do Projeto Orla no município de Balneário Rincão (SC), o presente estudo teve por objetivo evidenciar os mecanismos de construção do referido modelo, acompanhando e analisando os procedimentos técnicos propostos pelo Ministério do Meio Ambiente e entidades associadas, registrando as possibilidades, as potencialidades e os desafios do processo. Neste sentido, buscou-se no presente trabalho contribuir para o aperfeiçoamento dos mecanismos e processos de gestão integrada no que se refere aos procedimentos iniciais de implantação do Projeto Orla em um município de recente criação (2013).

\section{Metodologia}

\section{1. Área de estudo}

O presente trabalho teve como área de estudo a localidade de Balneário Rincão, no Litoral Sul do Estado de Santa Catarina (Figura 1), a qual foi efetivada como município a partir do ano de 2013 ao ser emancipada da cidade de Içara. Balneário Rincão compreende uma área territorial de aproximadamente $64,6 \mathrm{~km}^{2}$, na qual se distribui uma população estimada, para o ano de 2015, de 12.018 habitantes (IBGE, 2016). Entretanto, durante a alta temporada, há um fluxo de até 150.000 pessoas/dia (PMBR, 2016).

Balneário Rincão possui cerca de $13 \mathrm{~km}$ de orla exposta, apresentando praias arenosas com formação de dunas frontais e dunas interiores, além de conter sete lagoas (seis de água doce) localizadas a menos de $2 \mathrm{~km}$ do mar. A região possui inclusive importância na perspectiva histórica pré-colombiana, pela presença de sítios arqueológicos de tradição Tupi-Guarani e Sambaquis. Quanto à infraestrutura turística, destacam-se duas plataformas de pesca que adentram ao mar, sendo que a primeira (boreal) possui cerca de $500 \mathrm{~m}$ e a segunda (austral), cerca de $400 \mathrm{~m}$.

Considerando a gestão conservacionista dos territórios, além da aplicação de um regimento específico para a zona costeira, o município de Balneário Rincão também apresenta cerca de um terço de seu território (aproximadamente 21,5 km²) categorizado na qualidade de Área de Proteção Ambiental (APA) (Figura 1). A Área de Proteção Ambiental da Baleia Franca inclui o município de Balneário Rincão como seu limite sul de abrangência (2849'35.6'S 49¹3'09.9'W) e se estende até seu limite norte na Ilha de Santa Catarina (2746'09.6”S 48²8'30.1”W), compreendendo uma área total de aproximadamente 156.100 ha (Brasil, 2000; ICMBio, 2016). Dentre as finalidades para criação da APA, destaca-se a proteção da baleia franca austral Eubalaena australis, espécie que sofreu severas reduções populacionais até a década de 1920 (mais de 95\%) e que, a partir de planos 


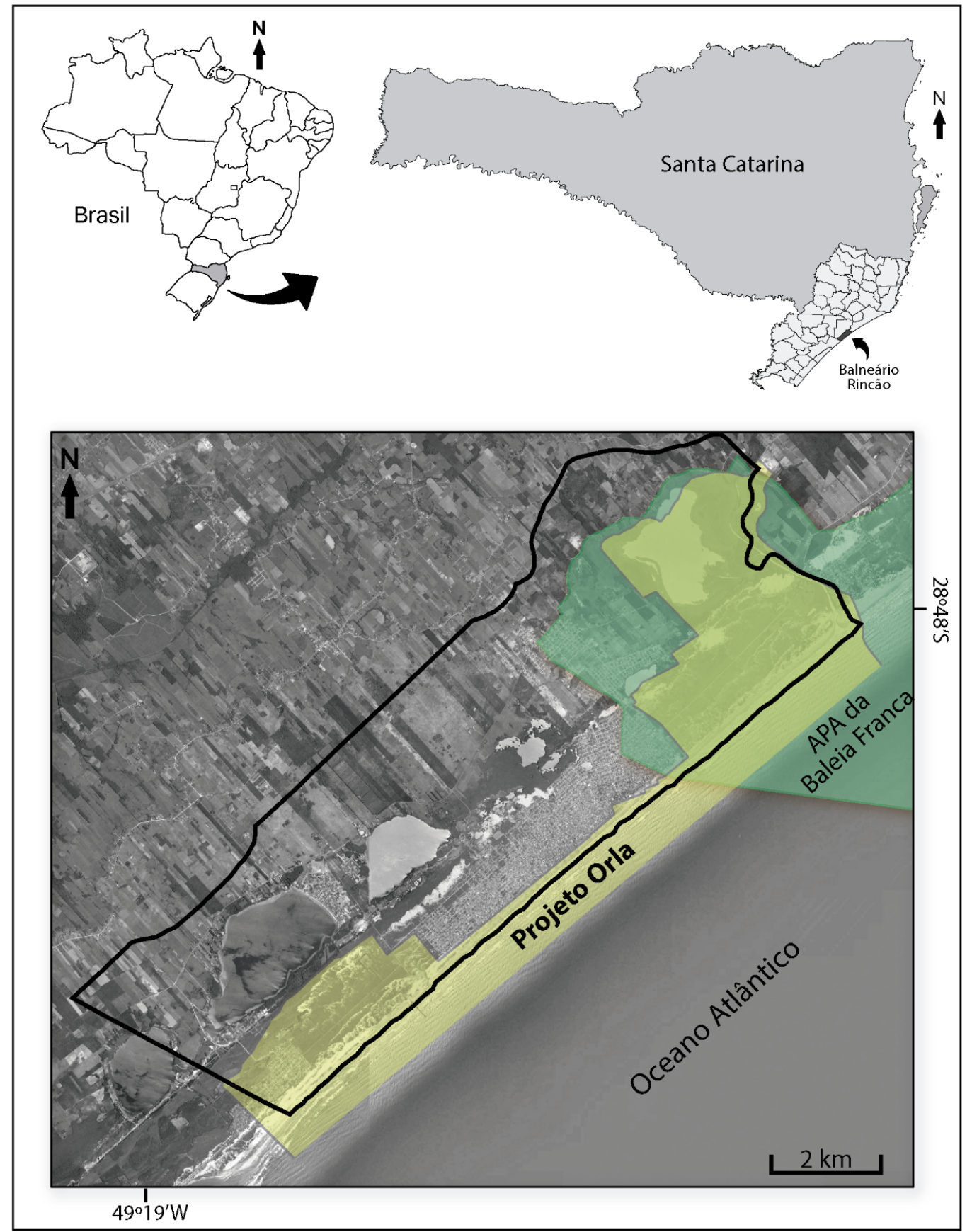

FIGURA 1 - Localização do município de Balneário Rincão. Destacam-se na imagem de satélite os limites do município estudado (linha preta), a porção de território correspondente à Área de Proteção Ambiental da Baleia Franca (área em verde) e a porção delimitada para implementação do Projeto Orla (área em amarelo). 
de conservação consistentes (como a proibição da caça e a própria criação da APA), demonstrou uma retomada no crescimento populacional (Reilly et al., 2013). Além disso, está prevista a elaboração do Plano de Manejo para a APA da Baleia Franca, instrumento que estabelecerá o zoneamento econômico-ecológico da área, buscando a organização do território em um contexto de qualidade ambiental e desenvolvimento sustentável, com a melhoria das condições de vida da população (Brasil, 2002).

\subsection{Análise de dados}

A presente pesquisa adotou uma abordagem de registro de dados qualitativos, tanto através de análise documental como de instrumentos de investigação participativa. Compreende-se que a variedade de procedimentos para a coleta de dados auxilia na aceitação do pesquisador pelo grupo, com ganho de confiança e, inclusive, diminuindo a interferência do pesquisador quanto à fidedignidade das informações obtidas (Gil, 2008; Albuquerque et al., 2010). A pesquisa documental se utilizou restritamente de fontes primárias, definidas por documentos com informação escrita, que ainda não haviam sofrido tratamento analítico e/ou contribuição alóctone, sendo, então, elaboradas por autores isolados e diretamente associados ao Projeto Orla (Angrosino, 2009).

De modo geral, o levantamento de dados ocorreu predominantemente de forma direta, com o recolhimento de informações por meio da utilização das técnicas de observação participativa. Neste contexto, a proposta metodológica desta pesquisa utilizou com maior ênfase a observação participante, com o pesquisador inserido nas atividades cotidianas do grupo, acompanhando eventos associados ao Projeto Orla no município de Balne- ário Rincão, como oficinas, reuniões e até mesmo conversas informais.

\section{Resultados}

O município de Balneário Rincão assinou o Termo de Adesão ao Projeto Orla dia 15 de maio de 2013, seguido por sua apresentação à comunidade (01 de março de 2014) e do início das oficinas de implementação por técnicos capacitados (26 de março de 2014 a 26 de março de 2015). Os dados obtidos por meio de fontes primárias e da observação participativa permitiram a estruturação dessas informações em "processos-chave", divididos em: Fundamentação teórico-prática, Caracterização territorial e Avaliação integrada.

\subsection{Fundamentação teórico-prática}

A primeira etapa do projeto foi direcionada à realização de oficinas com a apresentação e a contextualização do Projeto Orla, seguindo a metodologia indicada pelos guias de procedimentos técnicos fornecidos pelo MMA. Representantes da coordenação estadual do Projeto e de instituições envolvidas no processo de gerenciamento costeiro apresentaram suas atribuições frente à implementação e à execução deste instrumento de gestão, utilizando-se de seu formato integrado e participativo.

A Coordenação de Projetos Especiais da Superintendência do Patrimônio da União no Estado de Santa Catarina (SPU-SC) apresentou as principais incumbências do órgão e temas relacionados. Dentre elas, estão o ordenamento da utilização dos espaços públicos, a ocupação do território brasileiro na sua história e a problemática existente nas cidades que afetam a natureza, principalmente o mar. Neste 
contexto, foram apresentadas informações básicas sobre o significado e a descrição do que se denomina "Bens da União", bem como sobre os três direitos coletivos e sobre os limites previstos da metodologia do Projeto Orla. Desse modo, foram apresentados os desafios para gestão costeira, sobretudo, no que se refere às vantagens para os municípios que aderiram ao Projeto Orla, bem como as atribuições das coordenações estadual e municipal.

Neste processo de capacitação, foi concedido espaço para a representante da Secretaria de Estado do Planejamento, que discorreu sobre o Gerenciamento Costeiro (GERCO) e seus objetivos, sua abrangência territorial e base legal, incluindo os fundamentos sobre o zoneamento ecológico-econômico costeiro, o Plano de Gestão da Zona Costeira e sobre o Sistema de Informações do Gerenciamento Costeiro (SIGERCO). De acordo com os procedimentos previstos na metodologia, representantes da prefeitura apresentaram as propostas e projetos previstos pela administração municipal para a orla do Balneário Rincão. Dentre estas propostas, destacam-se as seguintes: a drenagem, o observatório das baleias, os postos salva-vidas, a via perimetral, os acessos à praia, o calçadão, a fixação da barra do Rio Urussanga, as passarelas de acesso, o comércio sazonal, os espaços esportivos, a praça de eventos, as áreas para regularização fundiária e o parque das dunas. Nesta fase também foi abordada a APA da Baleia Franca durante explanação realizada por um analista ambiental do Instituto Chico Mendes de Conservação da Biodiversidade (ICMBio).

O instrutor do projeto liderou e mediou grande parte das atividades, sempre abrindo espaço para a intervenção dos participantes, sendo eles representantes públicos ou da sociedade civil organizada. A importância da participação integrada da sociedade civil organizada, do GI-GERCO e, também, de órgãos estaduais no processo de implementação do
Projeto Orla foi enfatizada diversas vezes, tanto pela representante da SPU-SC quanto por servidores da prefeitura municipal (instrutor e coordenadora do Projeto Orla). Nesse contexto, também se estimulou o envolvimento de outros diversos órgãos, como o Ministério Público, a Secretaria de Estado de Planejamento, a Capitania dos Portos, o Corpo de Bombeiros e, inclusive, a Universidade do Extremo Sul Catarinense (UNESC). Quanto à integração de órgãos/instituições intimamente envolvidos com a responsabilidade ambiental, evidenciou-se a convocação da Empresa de Pesquisa Agropecuária e Extensão Rural de Santa Catarina (EPAGRI), a Fundação do Meio Ambiente (FATMA), a Polícia Militar Ambiental, o ICMBio e o Comitê Gestor da Bacia do Rio Urussanga.

Ao longo deste processo de capacitação, buscou-se ressaltar a importância do disciplinamento do uso do ambiente costeiro, sobretudo no que concerne às áreas sob domínio da União. Nesse sentido, evidencia-se a necessidade de um sistema integrado e direcionado ao comum acordo entre o interesse coletivo e a legislação.

\subsection{Caracterização territorial}

As atividades da etapa oficina I se iniciaram com a delimitação, em decisão consensual, da orla de Balneário Rincão. Sequencialmente, o instrutor e a coordenação municipal do Projeto estabeleceram dois setores mais abrangentes para a área (Setor 01 - Barra Velha e Setor 02 - Centro) e uma subdivisão adicional de cinco trechos, buscando especializar o desenvolvimento do projeto (Figura 2). Com a demarcação dos cinco trechos, iniciou-se o diagnóstico de campo, tendo etapas desenvolvidas dentro de cada trecho e setor separadamente, a fim de gerar um levantamento minucioso da área de abrangência do Projeto Orla. 


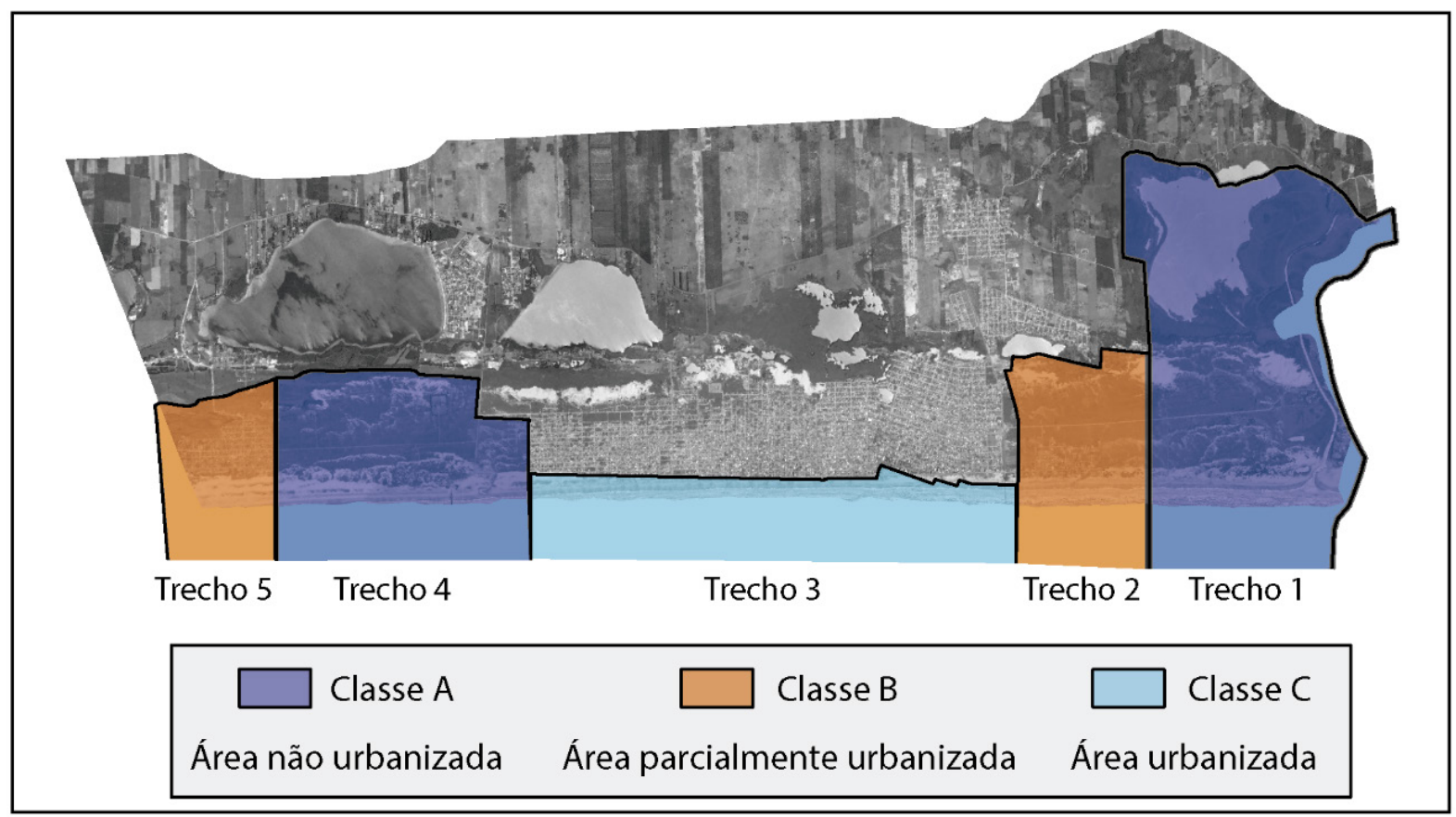

FIGURA 2 - Área do município de Balneário Rincão e divisão do território delimitado ao Projeto Orla em trechos, acompanhados de suas respectivas classes de ocupação.

Dada a diversidade dos sítios, o processo de diagnóstico territorial contemplou cerca de 15 dias de oficinas, culminando na classificação dos trechos de acordo com suas características paisagísticas, sendo: Classe $\mathrm{A}=$ área não urbanizada, Classe $\mathrm{B}=$ área parcialmente urbanizada e Classe $\mathrm{C}=$ área urbanizada.

Além dos limites territoriais para a orla marítima estabelecidos pelo Decreto Federal 5.300/04, a área de aplicação do Projeto Orla em Balneário Rincão considerou a sobreposição de territórios com a Área de Proteção Ambiental da Baleia Franca, na região nordeste do município, que apresenta regulamentação própria à sua ocupação.

A participação de membros desta APA na construção do Plano de Gestão Integrada da Orla foi considerada fundamental para garantir uma formulação integrada deste importante instrumento de gerenciamento costeiro. Neste contexto, deverão ser consideradas as definições presentes no Plano de Gestão Integrado (PGI) na construção do Plano de Manejo da presente APA, que está em andamento e vem seguindo uma metodologia inovadora no país, por meio da abertura de um espaço maior para a participação da sociedade, na perspectiva da gestão do ambiente marinho-costeiro de forma integrada efetivamente participativa.

Nesse processo, também foram realizados o diagnóstico de campo e a formulação de cenários para a orla marinha, considerando os parâmetros ambientais, sociais e econômicos observados em campo. 


\subsection{Avaliação integrada}

A construção participativa do "Quadro Síntese I" foi composta com os seguintes itens: (i) configuração do local e usos, (ii) problemas potenciais, (iii) projetos previstos e/ou em implantação. $\mathrm{Na}$ sequência, ocorreu a construção do "Quadro Síntese II", seguindo a mesma metodologia proposta nos manuais de implementação do Projeto Orla, apresentando os itens: (iv) atividades geradoras e (v) efeitos e impactos associados ao problema. Sequencialmente ocorreu a produção conjunta de um texto sobre como se comportam os cenários para o espaço local, levando em consideração a situação atual, a tendência e o cenário desejado.

Finalizando as etapas da oficina I, o instrutor, com a participação dos presentes, realizou a construção do quadro "Classificação das Unidades da Paisagem", para cada um dos cinco trechos, descrevendo os seguintes parâmetros: trecho da orla, características físicas, estágio de urbanização, tipologia de urbanização, configuração paisagística da urbanização, acesso, classificação e observações gerais. Após esta etapa, foram sintetizados os quadros de cada trecho dos dois setores, o que gerou a formulação de um zoneamento prévio da área de abrangência do Projeto.

Nas reuniões seguintes, objetivou-se a construção do regimento interno do Comitê Gestor da Orla e a análise das atividades anteriores. Para o entendimento da função do comitê, foi realizada com os participantes uma simulação com estudo de caso. Apesar de não estar prevista nos guias de procedimentos técnicos do Projeto Orla, a coordenação decidiu implementá-la por experiência adquirida em outros municípios.
Todas as atividades desenvolvidas na etapa oficina I realçaram a importância de um plano de gestão para toda a orla do município, enfatizando que o Projeto Orla tem como objetivo organizar este espaço do território municipal. Tais aspectos configuram-se como questões centrais, tendo em vista, a exemplo da maioria dos municípios do litoral brasileiro, a existência de grave processo de ocupação humana desordenada deste espaço, tomando, por exemplo, as casas construídas sem planejamento e muitas delas embargadas, como as casas construídas e posteriormente tomadas pelas dunas no bairro de Barra Velha, no município de Balneário Rincão.

Desta forma, este instrumento se destaca na perspectiva do disciplinamento e da gestão do espaço da faixa da orla de forma integrada, porém, esse processo deve entrar em convergência com os outros instrumentos instituídos ou em processo de instituição no território do município para que seus objetivos sejam alcançados de modo eficiente. Nesse contexto, o Plano de Gestão Integrada da Orla Marítima de Balneário Rincão - PGI - deverá integrar-se aos demais instrumentos de planejamento territorial que estão sendo elaborados no município. Dentre eles estão: Plano Diretor, Plano de Saneamento Básico, Plano de Resíduos Sólidos, Plano de Mobilidade Urbana, Regularização Fundiária, Plano de Manejo da APA da Baleia Franca e Plano de Gerenciamento Costeiro.

Assim, torna-se muito importante o acompanhamento integral dos trabalhos e a participação nas oficinas dos representantes das entidades da sociedade civil organizada, dos órgãos que fazem parte do grupo de integração do gerenciamento costeiro e demais órgãos nos níveis municipal, estadual e federal, conforme previsto neste projeto. 


\section{Discussão}

O território do município de Balneário Rincão está inserido em um espaço que se caracteriza pela intersecção entre vários instrumentos de gestão territorial, contemplando diversos níveis e escalas de planejamento e gestão. Neste contexto, o município insere-se no processo de ordenamento por meio do Plano Diretor Municipal, do Plano de Manejo da APA da Baleia Franca (em construção) e do Plano de Gestão Integrado da Orla. Neste sentido, a falta de políticas públicas voltadas para a gestão integrada para o seu ordenamento territorial poderá causar sérios conflitos.

Nos processos de gestão territorial, a participação da comunidade durante todo o processo é de extrema importância, colocando-se em evidência devido ao seu modo de produção autônomo, por meio de sua capacidade auto-organizadora na busca da satisfação de suas necessidades básicas (materiais e intangíveis), e heterônomo, no fortalecimento do controle da gestão do patrimônio natural e dos serviços coletivos (Seixas, 2005; Vieira, 2011), principalmente na zona costeira, por possuir áreas que são de uso comum e de patrimônio da União. A utilização de metodologias participativas constitui um importante caminho para tomada de decisão, pois possibilita a articulação das ideias e dos saberes populares locais e a sua integração com o conhecimento científico, além de um compartilhamento de uma visão sistêmica do mundo, de uma ética ecológica e do reconhecimento da importância do diálogo de saberes nos espaços de planejamento e gestão (Verdejo, 2006; Vieira et al., 2010). O conhecimento empírico adquirido pela população local constitui-se em um importante fator necessário para uma melhor compreensão das necessidades e características que nem sempre estão inclusas nos estudos técnicos realizados, por parte da gestão pública, principalmente nos níveis nacional e estadual.

Com a recente emancipação/efetivação de Balneário Rincão como município (2013), as carências na sua infraestrutura ficaram mais expostas, dentre elas o saneamento básico. Mesmo considerando que as obras necessárias estão previstas pela administração pública, ele ainda busca o levantamento de verbas a partir da elaboração do Plano Diretor Municipal. A participação e a colaboração de técnicos, principalmente no que se refere aos aspectos socioecológicos, ainda necessitam de um melhor aperfeiçoamento em relação ao projeto, onde pode ser percebida uma visão ainda fragmentada com relação às questões ambientais em alguns momentos das discussões, distanciando-se do principal objetivo do Projeto Orla, que é a preservação dos ambientes costeiros.

Em determinados momentos do processo de discussão e capacitação, os responsáveis pela coordenação das atividades demonstraram que necessitavam eles mesmos de uma melhor formação, sobretudo no que se refere às questões ambientais, o que gerou a proposição de soluções inapropriadas para com a proteção ambiental, a exemplo dos aspectos relacionados com a questão do saneamento básico. Tais lacunas precisam ser revistas, na perspectiva da proposição de soluções eficazes e adequadas às características ambientais locais e que estejam em conformidade com o equilíbrio do meio ambiente. Neste sentido, é de fundamental importância o papel da universidade para o aperfeiçoamento dos processos de gestão pública ambiental, com a realização de estudos e projetos, na busca de novas ideias e estratégias de ação, integrando o conhecimento científico e o saber local das comunidades tradicionais. Esta linha de reflexão universidade/sociedade contribuiu para deflagrar este estudo de caso, onde grupos sociais comparti- 
lham territórios com a universidade, visando mais do que à produção e à difusão de conhecimentos, mas também à transferência e à partilha do saber em benefício da coletividade (Girard et al., 2011).

Ressaltamos a importância da construção de espaços públicos não estatais para a resolução dos conflitos nos processos de gestão e planejamento, conforme os princípios básicos do ecodesenvolvimento territorial, o qual tem como enfoque a participação da comunidade como avaliadora e implementadora no desenvolvimento de projetos e gestão dos recursos comuns, buscando construir um modelo de território sustentável para moradores que dependem destes recursos para a sua sobrevivência (Sachs, 1986; Berkes, 2005; Sachs, 2007). Também é primordial o fortalecimento comunitário por meio de processos educativos e de sensibilização ambiental, buscando-se integrar os diversos instrumentos e espaços de gestão pública ambiental, tais como os Conselhos Gestores e os Comitês de Bacias Hidrográficas, as associações de moradores, as ONGs e demais formas de organização da sociedade, criando uma linha de conexão com estes órgãos de gestão, conduzindo a um processo de participação na direção da cogestão (Marroni \& Asmus, 2005).

Neste sentido, também no que se refere ao município onde este trabalho foi desenvolvido, pode-se destacar algumas instituições e órgão públicos, tais como a Secretaria de Estado de Planejamento, a EPAGRI, a FATMA, a Polícia Militar Ambiental, o IBAMA e o ICMBio, a UNESC - Universidade do Extremo Sul Catarinense, o Ministério Público Federal e Estadual, o Comitê Gestor da Bacia do Rio Urussanga e a Capitania dos Portos. Considerando, portanto, o contexto em que o Projeto Orla está sendo desenvolvido, constituem fatores fundamentais para uma efetiva consolidação do Projeto Orla como instrumento de gestão pública socioambiental a participação e o empoderamento da comunidade por meio da sua capacitação e participação efetiva em todo o processo.

\section{Considerações finais}

Compreende-se que pela histórica importância socioeconômica e pelo capital natural da costa brasileira, onde coexistem atividades de elevado impacto poluidor e recursos ambientais de extrema importância, a busca por um modelo de gestão baseado na integração e na participação efetiva da sociedade se torna imprescindível.

A exemplo do presente estudo, utilizando-se de metodologia qualitativa para acompanhar o processo implantação do Projeto Orla no município de Balneário Rincão, foi possível analisar e discutir a representatividade dos envolvidos no processo de desenvolvimento desse mecanismo de gestão e a real avaliação de seu fundamento participativo.

No contexto das etapas que puderam ser acompanhadas, constataram-se algumas dificuldades por parte de representantes do poder público em aceitar e valorizar a participação da sociedade neste processo de gestão compartilhada, o que ressalta a necessidade de um maior preparo desses servidores, com aprofundamento do processo de capacitação direcionado à construção de políticas públicas participativas, a partir de uma análise reflexiva das realidades individuais e coletivas.

Tendo como referência e alternativa ao modelo hegemônico atual de desenvolvimento o conceito de ecodesenvolvimento territorial, os processos de sensibilização e de mobilização da sociedade no contexto do projeto orla poderão avançar de forma transgressiva e inovadora, indo além da compreensão acerca das realidades do desenvolvimento regional e local. Nesta perspectiva de participação, a comunidade surge não somente como fonte de 
informação, mas como parte de uma realidade de natureza social, e contribui ativamente no processo de construção coletiva. Assim, conforme os preceitos e fundamentos da gestão integrada, a utilização de instrumentos para a elaboração de diagnósticos socioambientais efetivamente participativos não deve se pretender unicamente no registro de dados dos participantes, mas, sim, que estes iniciem um processo de autorreflexão sobre os seus próprios problemas e as possibilidades para solucioná-los.

Nesta perspectiva, dentre os principais desafios identificados nesta fase inicial de implantação do Projeto Orla no município do Balneário Rincão, destaca-se a necessidade de uma motivação e um envolvimento de forma mais efetiva da comunidade. Essa sensibilização deve ultrapassar o nível dos movimentos sociais e representações da sociedade civil e atingir inclusive os próprios gestores públicos, responsáveis pela elaboração e pela execução

\section{Referências}

Albuquerque, U. P.; Lucena, R. F. P.; Cunha, L. V. F. C. Métodos e técnicas na pesquisa etnobiológica e etnoecológica. Recife: NUPPEA, 2010.

Allen, C. R.; Cumming, G. S.; Garmestani, A. S.; Taylor, P. D.; Walker, B. H. Managing for resilience. Wildlife Biology, 17, 337-349, 2011. doi:10.2981/10-084

Angrosino, M. Etnografia e observação participante. Porto Alegre: Artmed, 2009.

Berkes, F. Sistemas sociais, sistemas ecológicos e direitos de apropriação de recursos naturais. In: Vieira, P. F.; Berkes, F.; Seixas, S. C. (Eds.). Gestão integrada e participativa de recursos naturais: conceitos, métodos e experiências. Florianópolis: APED/Secco, p. 47-72, 2005.

Brasil. Lei $n^{\circ} 7.661$, de 16 de maio de 1988. Institui o Plano Nacional de Gerenciamento Costeiro e dá outras providências. Brasília: DOU de 18/5/1998. de políticas públicas, tais como o planejamento no uso e na ocupação do solo e a gestão dos recursos naturais, buscando procedimentos que possibilitem a construção de modelos participativos de desenvolvimento, tendo o ecodesenvolvimento territorial como referência e alternativa para a superação dos atuais impasses e obstáculos a serem superados para a construção de uma sociedade mais justa e ecologicamente prudente.

\section{Agradecimentos}

Agradecemos ao apoio do Programa de Pós-Graduação em Ciências Ambientais da Universidade do Extremo Sul Catarinense - UNESC - e ao Laboratório de Gestão de Gestão Integrada de Ambientes Costeiros, que possibilitou o desenvolvimento desta pesquisa.
Brasil. Lei $n^{\circ}$ 9.433, de 8 de janeiro de 1997. Institui a Política Nacional de Recursos Hídricos, cria o Sistema Nacional de Gerenciamento de Recursos Hídricos, regulamenta o inciso XIX do art. 21 da Constituição Federal, e altera o art. $1^{\circ}$ da Lei ${ }^{\circ}$ 8.001, de 13 de março de 1990, que modificou a Lei n ${ }^{\circ} 7.990$, de 28 de dezembro de 1989. Brasília: DOU de 09/1/1997.

Brasil. Constituição da República Federativa do Brasil. São Paulo, Atlas, 1998.

Brasil. Decretos $/ n^{\circ}$, de 14 de setembro de 2000. Dispõe sobre a criação da Área de Proteção Ambiental da Baleia Franca, no Estado de Santa Catarina, e dá outras providências. Brasília: DOU de 14/9/2000.

Brasil. Decreto $n^{\circ} 4.297$, de 10 de julho de 2002. Regulamenta o art. $9^{\circ}$, inciso II, da Lei $\mathrm{n}^{\circ} 6.938$, de 31 de agosto de 1981, estabelecendo critérios para o Zoneamento Ecológico-Econômico do Brasil - ZEE, e dá outras providências. Brasília: DOU de 11/7/2002. 
Brasil. Decreto n. ${ }^{\circ}$ 5.300, de 7 de dezembro de 2004. Regulamenta a Lei $\mathrm{n}^{\circ} 7.661$, de 16 de maio de 1988, que institui o Plano Nacional de Gerenciamento Costeiro - PNGC, dispõe sobre regras de uso e ocupação da zona costeira e estabelece critérios de gestão da orla marítima, e dá outras providências. Brasília: DOU de 8/12/2004.

Brasil. Lei $n^{\circ} 12.651$, de 25 de maio de 2012. Dispõe sobre a proteção da vegetação nativa; altera as Leis n ${ }^{\circ} \mathrm{s} 6.938$, de 31 de agosto de 1981, 9.393, de 19 de dezembro de 1996, e 11.428, de 22 de dezembro de 2006; revoga as Leis $n^{\circ} \mathrm{s}$ 4.771, de 15 de setembro de 1965, e 7.754, de 14 de abril de 1989, e a Medida Provisória n ${ }^{\circ}$ 2.166-67, de 24 de agosto de 2001; e dá outras providências. Brasília: DOU de 28/5/2012.

Cymbalista, R.; Santoro, P. F. Planos diretores: processos e aprendizados. São Paulo: Instituto Pólis, 2009.

Gil, A. C. Métodos e técnicas de pesquisa social. 6. ed. São Paulo: Atlas, 2008.

Girard, P.; Levy, C.; Tremblay, G. Universidade e coletividade: como compartilhar conhecimentos? In: Tremblay, G.; Vieira, P. F. (Eds.). O papel das universidades no desenvolvimento local: experiências brasileiras e canadenses. Florianópolis: APED/Secco,2011. p. 219-249.

IBGE - Instituto Brasileiro de Geografia e Estatística. Atlas Geográfico das Zonas Costeiras e Oceânicas do Brasil. Rio de Janeiro: IBGE - Diretoria de Geociências, 2011.

IBGE - Instituto Brasileiro de Geografia e Estatística. Balneário Rincão: população estimada 2015. Disponível em: <http://cod.ibge.gov.br/85O>. Acesso em: abr. 2016.

ICMBio - Instituto Chico Mendes de Conservação da Biodiversidade. Área de Proteção Ambiental da Baleia Franca. Disponível em: $<$ http://www.icmbio.gov.br/apabaleiafranca>. Acesso em: maio 2016.

Marroni, E. V.; Asmus, M. L. Gerenciamento costeiro: uma proposta para o fortalecimento comunitário na gestão ambiental. Pelotas: USEB, 2005.

MMA - Ministério do Meio Ambiente. Sistema Nacional de Unidades de Conservação da Natureza. Brasília: MMA/ SBF, 2004.

MMA - Ministério do Meio Ambiente. Programa de Zoneamento Ecológico Econômico (2011). Disponível em: $<$ http://www.mma.gov.br>. Acesso em: set. 2014.
MMA/MP - Ministério do Meio Ambiente e Ministério do Planejamento Orçamento e Gestão. Projeto Orla: subsídios para um projeto de gestão. Brasíia: MMA, 2004.

MMA/MP - Ministério do Meio Ambiente e Ministério do Planejamento Orçamento e Gestão. Projeto Orla: guia de implementação. Brasília: MMA, 2005.

MMA/MP - Ministério do Meio Ambiente e Ministério do Planejamento Orçamento e Gestão. Projeto Orla: fundamentos para gestão integrada. Brasília: MMA/MP, 2006 .

MMA/MP - Ministério do Meio Ambiente e Ministério do Planejamento Orçamento e Gestão. Projeto Orla: manual de gestão. Brasília: MMA, 2006b.

Moraes, A. C. R. Contribuição para a gestão da zona costeira do Brasil: elementos para uma geografia do litoral brasileiro. São Paulo: Annablume, 2007.

Nakano, K. Projeto Orla: implementação em territórios com urbanização consolidada. Brasília: MP, 2006.

PMBR - Prefeitura de Balneário Rincão. Bem-vindo ao Balneário Rincão. Disponível em: $<$ http://balneariorincao. sc.gov.br/cms/pagina/ver/codMapaItem/4776>. Acesso em: abr. 2016.

Reilly, S. B.; Bannister, J. L.; Best, P. B.; Brown, M.; Brownell Jr., R. L.; Butterworth, D. S.; Clapham, P. J.; Cooke, J.; Donovan,G. P.; Urbán, J.; Zerbini, A. N. Eubalaena australis. The IUCN Red List of Threatened Species 2013: e.T8153A44230386. Disponível em: $<$ http://dx.doi. org/10.2305/IUCN.UK.2013-1.RLTS.T8153A44230386. en>. Acesso em: abr. 2016.

Sachs, I. Ecodesenvolvimento: crescer sem destruir. São Paulo: Vértice, 1986.

Sachs, I. Rumo à ecossocioeconomia: teoria e prática do desenvolvimento. São Paulo: Cortez, 2007.

Seixas, C. S. Abordagens e técnicas de pesquisa participativa em gestão de recursos naturais. In: Vieira, P. F.; Berkes, F.; Seixas, C. S. (Eds.). Gestão integrada e participativa de recursos naturais: conceitos, métodos e experiências. Florianópolis: APED/Secco,2005. p. 73-105.

Verdejo, M. E. Diagnóstico Rural Participativo: um guia prático. Brasil: EMATER, 2006.

Vieira, P. F. Pesquisa-ação-formação em regiões-laboratório de Desenvolvimento Territorial Sustentável: a experiência 
do Núcleo Transdisciplinar de Meio Ambiente \& Desenvolvimento da Universidade Federal de Santa Catarina. In: Tremblay, G.; Vieira P. F. (Eds.).O papel das universidades no desenvolvimento local: experiências brasileiras e canadenses.Florianópolis: APED/Secco, p. 185-205, 2011.
Vieira, P. F.; Berkes, F.; Seixas, C. S. Gestão integrada e participativa de recursos naturais: conceitos, métodos e experiências. Florianópolis: APED/Secco, 2005.

Vieira, P. F.; Cazella, A.; Cerdan, C.; Carrière, J. P. Desenvolvimento territorial sustentável no Brasil: subsídios para uma política de fomento. Florianópolis: Secco, 2010. 